\title{
Elongated Hindguts in Desert-Living Dung Beetles (Scarabaeidae: Scarabaeinae) Feeding on Dry Dung Pellets or Plant Litter
}

\author{
Peter Holter $^{1^{*}}$ and Clarke H. Scholtz ${ }^{2}$ \\ ${ }^{1}$ Section of Terrestrial Ecology, Institute of Biology, University of Copenhagen, DK-2100 Copenhagen, \\ Denmark \\ ${ }^{2}$ Department of Zoology and Entomology, University of Pretoria, Pretoria 0002, Republic of South Africa
}

\begin{abstract}
${ }^{*}$ Correspondence to: Peter Holter, Section of Terrestrial Ecology, Institute of Biology, University of Copenhagen, Universitetsparken 15, DK-2100 Copenhagen Ø, Denmark. Phone number: +4551827047. E-mail: pholter@bio.ku.dk
\end{abstract}

ABSTRACT Most adult dung beetles (Scarabaeidae: Scarabaeinae) feed on fresh, wet dung of larger herbivorous or omnivorous mammals. As indigestible plant fragments are filtered out before ingestion, the food is presumed easily digestible. However, members of the desert-living scarabaeine genus Pachysoma (probably evolved from an ancestor closely related to the wet-dung feeding genus Scarabaeus) select dry dung pellets and/or plant litter. Thus they ingest a much higher proportion of refractory plant material which, interestingly, seems to be digested rather efficiently. This study investigates morphological modifications of the gut for this digestion in adults of eight Pachysoma species, both pellet and litter feeders. To ascertain hypothesized ancestral conditions, four fresh-dung feeding Scarabaeus species were also examined. The latter 
have the usual dung beetle gut consisting of a long, simple midgut, followed by an equally simple, much shorter hindgut of the same width. Lengths of midguts (M) and hindguts $(\mathrm{H})$ - divided by body length (B) for comparison between species of different size - are: 4.9-6.3 (M/B) and 0.7-0.8 (H/B), which is normal for dung feeders. In Pachysoma, lengths are 6.3-6.5 (M/B) and 1.0-1.4 (H/B) in pellet feeders, and 4.4-5.0 $(\mathrm{M} / \mathrm{B})$ and 2.0-2.5 (H/B) for litter feeders. Hindguts are still morphologically undifferentiated and of midgut width, but clearly longer, particularly in litter feeders. Presumably, plant fragments in the food are digested, at least partly, in the hindgut. If so, the morphological adaptation is unusual: simple elongation rather than expansion of part of the hindgut, as found in several other plant- or detritus-feeding scarabs.

KEY WORDS: digestion; gut morphology; plant litter feeding; Pachysoma; Scarabaeus

\section{INTRODUCTION}

Many species within the beetle superfamily Scarabaeoidea feed on various kinds of plant material, including leaves, rotting wood, roots and more or less humified plant litter. This requires specializations for digesting plant cell walls consisting of chemically recalcitrant components such as lignocellulose and various hemicelluloses. A recurrent theme in studies on gut structure and function in scarabaeoids, particularly larvae (Werner, 1926; Wiedemann, 1930; Wildbolz, 1954; Rössler, 1961; Bayon, 1980; Bayon and Mathelin, 1980; Lemke et al., 2003; Egert et al., 2005; Nardi et al., 2006; 
Andert et al., 2010; Huang et al., 2010; Sheng et al., 2012; Zheng et al., 2012), is that the hindgut - aided by microbial symbionts - is likely to play a key role in the digestion. Several species have a large, sac-like hindgut dilatation ("paunch"), with high microbial abundance, evidently functioning as a fermentation chamber.

By contrast, adult beetles of most species within the large subfamily Scarabaeinae (the "genuine dung beetles" in the scarabaeoid family Scarabaeidae), are specialized to eat fresh, wet dung of herbivorous or omnivorous mammals. Prior to ingestion, coarse particles, i.e. refractory plant fragments with a high proportion of lignocellulose, are filtered out of the dung by the highly modified mouthparts (e.g. Miller, 1961; Hata and Edmonds, 1983; Nel and Scholtz, 1990; Holter and Scholtz, 2011). Hence, ingested food consists of small particles only, including nutritious and easily digestible dung components such as bacteria and dead gut epithelial cells. With this way of feeding (reviewed by Scholtz, 2009), specializations of the gut for digesting refractory plant cell walls would seem unnecessary. Indeed, adult wet-dung feeders have a simple, long and coiled midgut without dilatations or diverticula, and an equally simple, much shorter hindgut (Umeya, 1960; Miller, 1961; Edmonds, 1974; Lopez-Guerrero, 2002).

Some adult Scarabaeinae, however, have adopted other kinds of food, e.g. the genus Pachysoma MacLeay (reviewed in Davis et al. (2008)) which is closely related to the wet-dung feeding genus Scarabaeus Linnaeus and probably evolved from Scarabaeuslike ancestors. The 13 known Pachysoma species, divided into three intrageneric phylogenetic lineages, have switched to feeding on dry dung pellets (of small ruminants, hares or rodents) and/or other detritus, mostly plant litter. They collect the material on the soil surface in their arid sand dune habitats along the west coast of southern Africa. As this dry and coarse food cannot be filtered, it must be chewed to become suitable for 
swallowing and digestion (which has led to unusual modifications of the mouthparts (Holter and Scholtz, 2011)). The non-lignocellulose dung components are therefore diluted in the guts of pellet feeders by large amounts of chewed refractory plant material. Some digestion of the latter would clearly be advantageous in the pellet feeders and even more so in litter feeders where, of course, the only food particles in the guts are plant fragments (Holter and Scholtz, 2007, 2011).

An assimilation efficiency of about $60 \%$ in one of the plant-litter feeding species indicates a rather efficient digestion of the plant fragments (Holter et al., 2009). This probably requires gut specializations not found in wet-dung feeders; and inspired by the above-mentioned studies of scarabaeoid larvae we hypothesized that modifications would be most likely in the hindgut. Therefore, the present study of the external morphology and length of the hindgut (and, if possible, the midgut) was carried out in eight species of Pachysoma, representative of all lineages and diets. To assess the presumed ancestral state of hindguts, four species of Scarabaeus were also examined. Results are briefly discussed in relation to the food and likely evolution of the species.

\section{MATERIALS AND METHODS}

Specimens of the following species were collected in western South Africa: Scarabaeus rugosus (Hausmann), Pachysoma aesculapius (Olivier) and P. glentoni (Harrison, Scholtz and Chown) at Leipoldtville (S32.21842 $\left.{ }^{\circ}, \mathrm{E} 18.43522^{\circ}\right)$, S. rugosus, S. (Kheper) bonellii (MacLeay), P. endroedyi (Harrison, Scholtz and Chown), $P$. hippocrates MacLeay and P. striatum Castelnau at Kommandokraal Farm (S31.50312 ${ }^{\circ}$, E17.20262 $), P$. hippocrates at Noup (S30.13910, E17.20262) and P. gariepinus 
Ferreira at Holgat River near Port Nolloth (S28.92998 , E16.77575'). In addition, $S$. rusticus (Boheman) was caught near Pretoria (S25.78333, E27.99577º, whereas $S$. rubripennis (Boheman), P. denticolle Péringuey and P. rotundigena Felsche were collected at NamibRand, Namibia (S24.87611 ${ }^{\circ}$, E15.90167º).

Beetles were killed by quick immersion into boiling water within a few hours after collection and their body length determined. If possible, the animals were dissected immediately afterwards and lengths of the fresh midgut and hindgut measured. When this was impossible, e.g. at NamibRand, the freshly killed beetles were preserved in $70 \%$ ethanol and processed later in the laboratory. Reliable measurement of the preserved, thin-walled and brittle midguts proved impossible, whereas the more robust hindguts could be measured. Ethanol-preserved guts (Fig. 1) were photographed using an Olympus SZX12 photomicroscope with F-View digital camera. Statistical analyses of gut lengths were performed using Sigma Plot 11.0 (C) Systal Software Inc.).

\section{RESULTS}

As the guts of all examined Scarabaeus species (listed in table 1) were very similar, only the hindgut of Scarabaeus rugosus is shown in Fig. 1A. Guts in two Pachysoma species - a pellet and a plant-litter feeder - are illustrated in Fig. 1B-D. Again, these examples cover the morphologies in the other pellet and litter feeders (cf. table 1). Generally, the morphological terminology follows Snodgrass (1935) and Edmonds (1974). 
Midguts in both Scarabaeus and Pachysoma are of the usual type in Scarabaeine dung beetles: long, coiled and of approximately the same width over the entire length. The anterior end of the hindgut is a very short, muscular section, the pylorus (or “proximal ileum" according to Umeya $(1960 ; 1974))$ which joins the midgut where the Malpighian tubules open into the gut. The pylorus is mostly much narrower than both midgut and posterior parts of the hindgut (Fig. 1A and B), but may be distended by gut contents in a completely filled gut (Fig. 1D). The remaining hindgut is a simple tube, approximately as wide as the midgut or - in litter feeders - slightly wider. Whereas hindguts are U-shaped in Scarabaeus (Fig. 1A) and pellet feeding Pachysoma species (Fig. 1B), the longer ones in litter feeders (Fig. 1C and D) have extra loops.

Table 1 shows intrageneric phylogenetic lineage (Pachysoma species only), diet, body length (B), length of midgut $(\mathrm{M})$ if known, and hindgut length $(\mathrm{H})$ of the examined species. For each individual, gut length has been divided by body length (M/B and H/B) to allow comparisons between beetles of different size. In S. rugosus, $P$. striatum, $P$. glentoni and P. hippocrates, hindgut lengths from both fresh and ethanolpreserved specimens were available, cf. Materials and Methods. In a general linear model with species and \pm preservation as independent variables and $\mathrm{H} / \mathrm{B}$ (logtransformed to normalize data) as dependent variable, there was a significant $(\mathrm{P}<0.0001)$ effect of species, but none $(\mathrm{P}=0.95)$ of preservation. $\mathrm{H} / \mathrm{B}$ values from fresh and preserved beetles are therefore pooled in Table 1.

Measured M/B values are about 4.9-6.3 for Scarabaeus species (i.e. the wet-dung feeders) and 4.4-6.5 for Pachysoma species. Thus, the genera overlap strongly as regards midgut length. Within Pachysoma, M/B values for pellet feeders (P.gariepinus, 
striatum and aesculapius) are 6.3-6.5, whereas those for litter feeders - entirely ( $P$. glentoni and hippocrates) or at least partly (P. endroedyi) - are 4.4-5.0. An ANOVA including all six species showed a significant $(\mathrm{P}<0.0001)$ overall species difference regarding $\mathrm{M} / \mathrm{B}$ values. In a subsequent multiple comparison (Holm-Sidak method) of all species pairs, pellet feeders had significantly $(\mathrm{P}<0.05)$ higher $\mathrm{M} / \mathrm{B}$ values than did litter feeders; differences within the two trophic groups were non-significant.

$\mathrm{H} / \mathrm{B}$ values in Table 1 for wet-dung feeders, pellet feeders and litter feeders (including $P$. endroedyi) are 0.7-0.8, 1.0-1.4 and 2.0-2.5, respectively, without overlap between trophic groups. In a statistical analysis similar to that of $\mathrm{M} / \mathrm{B}$ values (again with a significant $(\mathrm{P}<0.0001)$ overall species difference $)$, the $\mathrm{H} / \mathrm{B}$ value of any litter feeder was significantly $(\mathrm{P}<0.05)$ higher than that of any dung or pellet feeder. In species pairs consisting of a fresh-dung and a pellet feeder, differences were also significant $(\mathrm{P}<0.05)$ except for $S$. rusticus/P. denticolle.

\section{DISCUSSION}

Although our main purpose was to find out whether external appearance and length of hindguts reflect the diets of adult beetles within the closely related genera Scarabaeus (fresh, wet dung) and Pachysoma (dry dung pellets or plant litter), midgut lengths were also measured. M/B values of the examined species are 4.4-6.5, without consistent differences between the two genera. They are in the middle of the range 2.58.4 calculated from data in Lopez-Guerrero (2002) and Umeya (1960) for 19 Scarabaeinae (including 18 fresh-dung feeders, albeit not from the tribe Scarabaeini 
where Scarabaeus and Pachysoma belong) and hence typical, as is the midgut morphology. Within Pachysoma, measured pellet feeders have significantly $(\mathrm{P}<0.05)$ longer midguts (M/B values of 6.3-6.5) than do litter feeders (4.4-5.0). Possibly, the latter do not need a long midgut because much of their food is not digested in it (but perhaps in the hindgut, see below). Also, reduction of the midgut may have been required to make room for the large hindgut within the abdomen.

Behind a short and narrow anterior pylorus, the remaining hindgut (Fig. 1) is a simple tube of approximately the same width as the midgut in dung and pellet feeders, and a little wider in litter feeders. This morphology is characteristic of adult fresh-dung feeders within the Scarabaeinae (Umeya, 1960; Miller, 1961; Edmonds, 1974; LopezGuerrero, 2002), whereas many other larval or adult Scarabaeoidea (e.g. Wiedemann, 1930; Umeya, 1960, 1974; Lopez-Guerrero, 2002; Egert et al., 2005, Fonseca et al., 2011) have a differentiated hindgut with at least one expansion behind the pylorus. H/B values are $0.7-0.8,1.0-1.4$ and 2.0-2.5 in dung, pellet and litter feeders, respectively (Table 1), and thus increase with the content of coarse plant fragments in the ingested food. The length affects gut arrangement: whereas hindguts of fresh-dung and pellet feeders (Fig. 1A and B) are simply U-shaped - a common pattern in scarabaeine dung feeders (Umeya, 1960; Lopez-Guerrero, 2002) - those of litter feeders need two extra loops to be accommodated in the abdomen (Fig. 1C and D). From Umeya (1960) and Lopez-Guerrero (2002), H/B values of the above-mentioned 19 adult Scarabaeinae can be estimated. The largest (of Copris incertus) is 2.3; the others are 0.4-1.7, with 16 of them being below 1.5 (Lopez-Guerrero's data result in an H/B value of 2.4 for Phanaeus vindex, but Fig.1 in Becton (1930), quoted by Lopez-Guerrero, indicates a 
value of 0.8). This suggests that hindguts of litter feeding Pachysoma species are longer than those of most other adult Scarabaeinae.

It might be argued that gut length variations in the species studied here could be related to phylogeny rather than to diet. Whereas this cannot be dismissed as regards intergeneric differences, the "diet hypothesis" is supported within the genus Pachysoma (table 1). First, $\mathrm{H} / \mathrm{B}$ and $\mathrm{M} / \mathrm{B}$ values in pellet feeders are rather similar, without any clear relation to lineage. Second, within lineage 3, P. aesculapius, $P$. glentoni and $P$. hippocrates are supposed to be more closely related to each other than to P. endroedyi (Sole et al., 2005), but this is not reflected in the H/B and MB values. Hindgut elongation might also be attributed to increased requirements for reabsorption of water from gut contents, a process known to take place in insect hindguts (see e.g. Chown and Nicolson (2004) for review and references). However, it is difficult to see why the hindguts of litter feeders should become up to twice as long as those in pellet feeders, given that small dung pellets and plant litter on the sand surface of the desert seem to be equally dry. The really big difference should be between the wet-dung feeding Scarabaeus species on the one hand, and all the Pachysoma species with dry food on the other. But hindguts in some of the pellet feeders are only slightly longer than those of Scarabaeus species. Hence we prefer the "diet hypothesis" which implies that the evolutionary switch from wet-dung feeding with a low proportion of plant fragments in the ingested material to ingestion of dry food with increasing amounts of plant fragments has led to a gradual hindgut extension. This in turn indicates that the relatively efficient digestion of the plant material found by Holter et al. (2009) takes place, at least partly, in the hindgut as found in other scarabaeoids. If so, a larger 
volume for digestion of more plant material has arisen in an unusual way: by simple elongation.

Why did a large hindgut paunch - as seen in many scarabaeoid larvae - not evolve instead? Like several other flightless dung beetles (e.g. the South African Circellium bacchus (Davis et al., 2008) or the Argentine eucraniines (e.g. Philips et al., 2002)), the Pachysoma species have a compact body with a short and rather flat abdomen, confined between strongly sclerotized elytra and sterna. This body shape may facilitate the extensive walking and digging activity of these beetles. Given the limited abdominal space, extra hindgut volume in the form of an elongated, slim and flexible tube may have been simpler to accommodate than a bulky, inflexible paunch. The latter is probably more suitable in the large, soft and expansive abdomen of scarabaeoid larvae.

\section{ACKNOWLEDGEMENTS}

L. Stenseng (Copenhagen) assisted in the field and helped, together with R. Rønn (Copenhagen), in the production of Fig. 1. Also, help with collection and transport was given by J. Smolka (Lund). We are grateful to all of them.

\section{LITERATURE CITED}

Andert J, Marten A, Brandl R, Brune A. 2010. Inter- and intraspecific comparison of the bacterial assemblages in the hindgut of humivorous scarab beetle larvae (Pachnoda spp.). FEMS Microbiol Ecol 74:439-449. 
Bayon C. 1980. Volatile fatty acids and methane production in relation to anaerobic carbohydrate fermentation in Oryctes nasicornis larvae (Coleoptera: Scarabaeidae). J Insect Physiol 26:819-828.

Bayon C, Mathelin J. 1980. Carbohydrate fermentation and by-product absorption studied with labelled cellulose in Oryctes nasicornis larvae (Coleoptera: Scarabaeidae). J Insect Physiol 26:833-840.

Becton EM Jr. 1930. The alimentary tract of Phanaeus vindex Macl. (Scarabaeidæ). Ohio J Sci 30:315-323.

Chown SL, Nicolson SW. 2004. Insect Physiological Ecology, Mechanisms and Patterns. Oxford: Oxford University Press. 243 p.

Davis ALV, Frolov AV, Scholtz CH. 2008. The African Dung Beetle Genera. Pretoria: Protea Book House. 272 p.

Edmonds WD. 1974. Internal anatomy of Coprophanaeus lancifer (L.) (Coleoptera: Scarabaeidae). Int J Insect Morphol 3:257-272.

Egert M, Stingl U, Bruun LD, Pommerenke B, Brune A, Friedrich MW. 2005. Structure and topology of microbial communities in the major gut compartments of Melolontha melolontha larvae (Coleoptera: Scarabaeidae). Appl Environ Microb 71:4556-4566. Fonseca CRV, Barbosa MLL, Fernandez MFS. 2011. A hypothetical evolutionary history of passalid beetles narrated by the comparative anatomy of the hindgut (Coleoptera: Passalidae). Zootaxa 3012:1-20. 
Harrison JduG, Scholtz CH, Chown SL. 2003. A revision of the south-western African dung beetle subgenus Scarabaeus (Pachysoma) MacLeay, including notes on other flightless Scarabaeini (Scarabaeidae: Scarabaeinae). J Nat Hist 37: 305-355.

Hata K, Edmonds WD. 1983. Structure and function of the mandibles of adult dung beetles (Coleoptera: Scarabaeidae). Int J Insect Morphol 12:1-12.

Holter P, Scholtz CH. 2007. What do dung beetles eat? Ecol Entomol 32:690-697.

Holter P, Scholtz CH, Stenseng L. 2009. Desert detritivory: Nutritional ecology of a dung beetle (Pachysoma glentoni) subsisting on plant litter in arid South African sand dunes. J Arid Environ 73: 1090-1094.

Holter P, Scholtz CH. 2011. Re-establishment of biting mouthparts in desert-living dung beetles (Scarabaeidae: Scarabaeinae) feeding on plant litter - old structures reacquired or new ones evolved? J Morphol 272:1007-1016.

Huang SW, Zhang HY, Marshall S, Jackson TA. 2010. The scarab gut: A potential bioreactor for bio-fuel production. Insect Sci 17:175-183.

Lemke T, Stingl U, Egert M, Friedrich MW, Brune A. 2003. Physicochemical conditions and microbial activities in the highly alkaline gut of the humus-feeding larva of Pachnoda ephippiata (Coleoptera: Scarabaeidae). Appl Environ Microb 69:66506658.

Lopez-Guerrero Y. 2002. Anatomy and histology of the digestive system of Cephalodesmius armiger Westwood (Coleoptera, Scarabaeidae, Scarabaeinae). Coleopts Bull 56:97-106. 
Miller A. 1961. The mouth parts and digestive tract of adult dung beetles (Coleoptera: Scarabaeidae), with reference to the ingestion of helminth eggs. J Parasit 47:735-744.

Nardi JB, Bee CM, Miller LA, Nguyen NH, Suh S-O, Blackwell M. 2006. Communities of microbes that inhabit the changing hindgut landscape of a subsocial beetle. Arthropod Struct Dev 35:57-68.

Nel A, Scholtz CH. 1990. Comparative morphology of the mouthparts of adult Scarabaeoidea (Coleoptera). Entomol Mem Dep Agric Dev Rep S Afr 80:1-84.

Philips TK, Scholtz CH, Ocampo FC. 2002. A phylogenetic analysis of the Eucraniini (Coleoptera: Scarabaeidae: Scarabaeinae). Insect Syst Evol 33: 241-252.

Rössler ME. 1961. Ernährungsphysiologische Untersuchungen an Scarabaeidenlarven (Oryctes nasicornis L., Melolontha melolontha L.). J Insect Physiol 6:62-80.

Scholtz CH. 2009. Food and feeding in dung beetles. In: Scholtz CH, Davis ALV, Kryger U. Evolutionary Biology and Conservation of Dung Beetles. Sofia-Moscow: Pensoft Publishers, pp.121-146.

Sheng P, Huang S, Wang Q, Wang A, Zhang H. 2012. Isolation, screening, and optimization of the fermentation conditions of highly cellulolytic bacteria from the hindgut of Holotrichia parallela larvae (Coleoptera: Scarabaeidae). Appl Biochem Biotechnol 167:270-284.

Snodgrass RE. 1935. Principles of Insect Morphology. New York: McGraw-Hill Book Company, Inc. 667 p. 
Sole CL, Scholtz CH, Bastos ADS. 2005. Phylogeography of the Namib Desert dung beetles Scarabaeus (Pachysoma) MacLeay (Coleoptera: Scarabaeidae). J Biogeogr $32: 75-84$.

Umeya K. 1960. A comparative morphology of the alimentary tract in the adults of lamellicorn-beetles (Coleoptera). Mem Fac Agr Hokkaido Univ 3:60-113.

Umeya K. 1974. Anatomy of the alimentary canal of the genus Hexodon (Coleoptera, Scarabaeidae) endemic in Madagascar. Kontyû, Tokyo 42:44-50.

Werner E. 1926. Die Ernährung der Larve von Potosia cuprea Fbr. (Cetonia floricola Hbst.). Ein Beitrag zum Problem der Celluloseverdauung bei Insectenlarven. Z Morphol Ökol Tiere 6:150-206.

Wiedemann JF. 1930. Die Zelluloseverdauung bei Lamellicornierlarven. Z Morphol Ökol Tiere 19:228-258.

Wildbolz T. 1954. Beitrag zur Anatomie, Histologie und Physiologie des Darmkanals der Larve von Melolontha melolontha L. Mit Sch Entomol Ges 27:193-240.

Zheng W, Zhao Y, Zhang H. 2012. Morphology and ultrastructure of the hindgut fermentation chamber of a melolonthine beetle Holotrichia parallela (Coleoptera: Scarabaeidae) during larval development. Micron 43:638-642. 

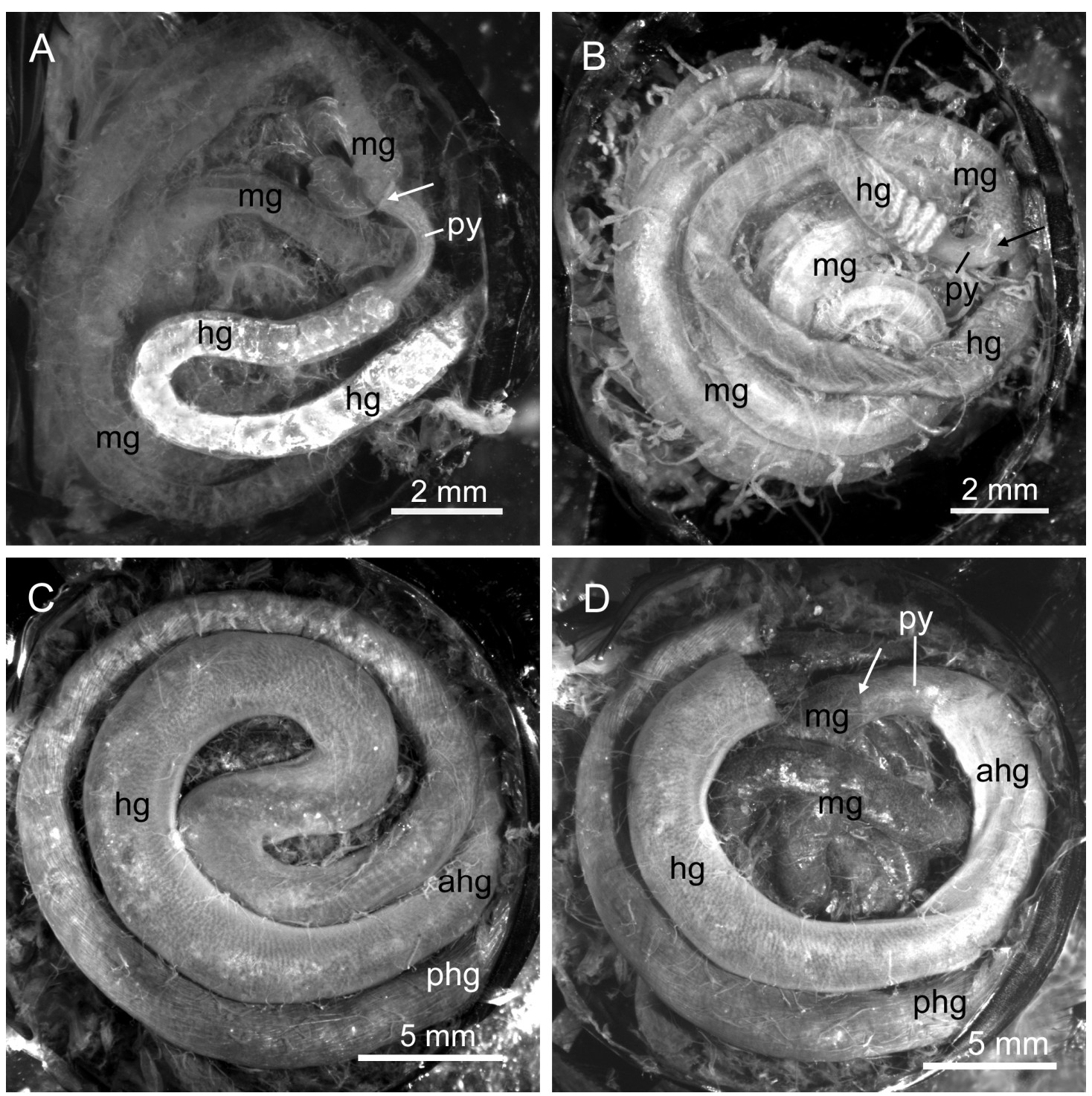

Fig.1. Dorsal views of hindguts (in situ, preserved in 70\% ethanol) in adult beetles of one Scarabaeus and two Pachysoma species. Anterior end of abdomen is to the left. A. Scarabaeus rugosus, wet-dung feeder. Midgut empty; white material in hindgut probably uric acid from Malpighian tubules. B. Pachysoma striatum, dry-pellet feeder. Entire gut empty. C. Pachysoma glentoni, plant-litter feeder. Entire gut filled. Midgut almost completely covered by the long, coiled hindgut. D. Same as C, but with part of the hindgut removed to show some of the midgut and the midgut/hindgut junction. ahg, anterior part of hindgut behind pylorus; hg, hindgut; mg, midgut; phg, posterior part of hindgut; py, pylorus (i.e. anterior end of hindgut); arrows indicate midgut/ hindgut (pylorus) junction. 
Table 1. Name, food, body length (B) and lengths of midgut $(\mathrm{M})$ and hindgut $(\mathrm{H})$, relative to $\mathrm{B}$, of the investigated Scarabaeus (S.) and Pachysoma (P.) species. For the Pachysoma species, intrageneric phylogenetic lineage is noted (bold number) after each name. Numerical data given as mean \pm standard error followed by the number of measured individuals (bracketed). Midguts of S. rubripennis, P.denticolle and P. rotundigena were not measured. Food information based on Harrison et al. (2003), Holter and Scholtz $(2009,2011)$ (P. glentoni, P. endroedyi) and unpublished observations by Scholtz ( $P$. rotundigena, $P$. aesculapius). 'Pellet' denotes dry dung pellet, and 'mainly pellets' implies that some plant detritus is occasionally included in the diet.

\begin{tabular}{|c|c|c|c|c|}
\hline $\begin{array}{l}\text { Species and, for } \\
\text { Pachysoma spp., } \\
\text { intrageneric lineage } \\
\text { (bold) }\end{array}$ & Food & $\mathrm{B}(\mathrm{mm})$ & $\mathrm{M} / \mathrm{B}$ & $\mathrm{H} / \mathrm{B}$ \\
\hline S. bonellii & Fresh dung & $26.2 \pm 1.24(5)$ & $4.86 \pm 0.305$ & $0.75 \pm 0.033$ \\
\hline S. rugosus & Fresh dung & $21.2 \pm 0.44(8)$ & $5.80 \pm 0.190$ & $0.74 \pm 0.011$ \\
\hline S. rubripennis & Fresh dung & $11.3 \pm 0.88$ & - & $0.69 \pm 0.022$ \\
\hline S. rusticus & Fresh dung & $24.0 \pm 0.95(5)$ & $6.27 \pm 0.276(5)$ & $0.82 \pm 0.026(5)$ \\
\hline P. denticolle $\mathbf{1}$ & Mainly pellets & $15.0 \pm 0.46(4)$ & - & $0.97 \pm 0.015$ \\
\hline P. rotundigena 1 & Mainly pellets & $23.5 \pm 1.46(5)$ & - & $1.20 \pm 0.071(5)$ \\
\hline P.gariepinus 2 & Pellets & $25.5 \pm 0.87$ (4) & $6.32 \pm 0.292$ & $1.03 \pm 0.069$ (4) \\
\hline P. striatum 2 & Pellets & $21.7 \pm 0.37(8)$ & $6.48 \pm 0.409$ & $1.11 \pm 0.026(8)$ \\
\hline P. aesculapius $\mathbf{3}$ & Mainly pellets & $26.4 \pm 0.40(5)$ & $6.30 \pm 0.263$ & $1.42 \pm 0.059$ (5) \\
\hline P. endroedyi $\mathbf{3}$ & $\begin{array}{l}\text { Plant litter } \\
\text { and/or pellets }\end{array}$ & $29.3 \pm 0.71(6)$ & $5.03 \pm 0.184$ & $2.11 \pm 0,025(6)$ \\
\hline P. glentoni $\mathbf{3}$ & Plant litter & $35.7 \pm 0.66(10)$ & $4.75 \pm 0.192(5)$ & $2.54 \pm 0.093(10)$ \\
\hline P. hippocrates $\mathbf{3}$ & Plant litter & $29.3 \pm 0.84(7)$ & $4.36 \pm 0.322(4)$ & $2.04 \pm 0.121(7)$ \\
\hline
\end{tabular}

